\title{
Morbility and mortality for cervical cancer in the isle of youth, 2003-2015
}

\begin{abstract}
A retrospective descriptive study characterizes the morbidity and mortality by cervical cancer during 2003-2015 in the Isle of Youth. Were studied 381 women with this diagnostic and 17 patients that died by this cause during this period. During 2014-2015 were identified $38 \%$ of all; in 2007 and 2014 the age average was low to 40 years old. The first delivery before 20 years old, the first sexual relations before 16 years old y tobacco were in $40 \%$ of the patients. Were studied 11 pregnant and 39\% hadn't last abnormal Pap smear. The colposcopy-histology correlation was $88 \%$ and the stage 0 -I represented the $81 \%$. The surgery was the main treatment option, the combination hysterectomy/conization was used in $68 \%$ of the patients and only $2 \%$ required palliative treatment. The mortality shows stable behavior and 2012 was the period with more rate, 7 patients. The age average in these patients was 55-60 years old. The global survival was more $95 \%$ in the first year and more to $85 \%$ in 5 years.
\end{abstract}

Keywords: Cervical cancer, Morbility, Mortality, Pregnant
Volume 9 Issue I - 2018

\author{
Heenry Luis Dÿvila Gmez,' Zaskia Matos \\ Rodrguez, ${ }^{2}$ Dayam Martnez Rodrguez, ${ }^{3}$ Abel \\ Garca Valdes, ${ }^{3}$ Oscar Esquivel $\mathrm{Daz}^{4}$ \\ 'Specialist 2 nd Degree in Gynecology and Obstetrics, Máster in \\ Integral Attention to the Woman, Hospital General Educational \\ Heroes of the Baire, Cuba \\ ${ }^{2}$ Specialist Ist Degree in Gynecology and Obstetrics, Hospital \\ General Educational Heroes of the Baire, Cuba \\ ${ }^{3}$ Specialist I st Degree in Gynecology and Obstetrics, Máster in \\ Integral Attention to the Woman, Hospital General Educational \\ Heroes of the Baire, Cuba \\ ${ }^{4}$ Specialist Ist Degree in Gynecology and Obstetrics, Specialist \\ Ist Degree in Integral General Medicine, Hospital General \\ Educational Heroes of the Baire, Cuba
}

\begin{abstract}
Correspondence: Heenry Luis Dÿvila Gmez, Specialist 2nd Degree in Gynecology and Obstetrics, Ist Degree in Integral General Medicine, Mÿster in Integral Attention to the Woman, Mÿster in Medical Education, Auxiliary professor, Investigator Attach?, Hospital General Educational Heroes of the Baire, Island of the Youth, Cuba, Email heenry@infomed.sld.cu
\end{abstract}

Received: December 27, 2017| Published: February 21, 2018

\section{Introduction}

The cervix cancer is the third more common among the women in the entire world, only preceded by the cancer of he/she suckles and the colorrectal. The pick of incidence happens between the fourth and fifth decade of the life and it is calculated that the mortality is six times adult in women of more than 50 years for a rate of incidence of 7,6 for 100000 with regard to the young women that it is of 1,2 for $100000 .{ }^{1}$

At world level every year they are diagnosed approximately half millions of new cases of cervical cancer. In Chile, an incidence of $30 \times 100000$ women is calculated and they die around 900, the rate of mortality is of 9,6 $\times 100000$. In the United States more than 10 000 new cases are diagnosed annually. In Spain the adjusted annual rate of cervix cancer, excluded the carcinoma in situ, is 7, 2 for 100 000 women and the rate of mortality is of 2,7 for 100000 women. In Mexico it constitutes the first cause of morbid-mortality for cancer in the feminine sex. ${ }^{2}$

Cuba is one of the countries of Latin America with more rate of incidence of cancer in a general way. According to reports of the Statistical Annual in the year 2008, the cancer of uterine neck occupied the fifth place among the main causes of death, with a total of 457 deceased's and a rate of 12,5 for 100000 women in the group of ages of 40 to 59 years and of 19,8 in the group of 60 to 79 years. This reflective global behavior an increment in 2,6 times in comparison with the year 1970 and with 14 more cases, regarding the previous year. ${ }^{3}$

The main statistical report of the Health in reflective Cuba for the year 2014 (last published edition) the third higher incidence of the last 24 years, with 1461 cases. In that year they happened 471 deaths for this illness, constituting the fifth general cause although if it is considered that an appreciable number of deceased's is not still specified the localization between body and uterine neck, it is reasonable to think that the real mortality is bigger. ${ }^{4}$

The Isle of Youth continues being the territory of the country with more percentage of cases of wicked neoplasia in comparison with the total population. For the year 2012 the epidemic situation has not improved and with an adjusted rate of 131, 0 for 100 thousand inhabitants, it continued being the bigger than the country and 1,1 times adult to the national rate. In the year 2014 the adjusted rate was of 150,4 for 100000 inhabitants, 1,2 times adult to that of the country and equally, the biggest national registration. ${ }^{4}$

In this theoretical context it is necessary to open a parenthesis to an unusual combination: cancer and pregnancy. The cancer is a strange condition during the pregnancy. This coincidence is estimated in one of each 1000 gestations. ${ }^{5}$ Every year they are diagnosed in the United States between 3500 and 6000 new cases of wicked illnesses, representing the third part of the maternal deaths. ${ }^{6}$ due to the general tendency of postponing the reproductive stage to superior ages and the effect that it has more than enough this phenomenon have the techniques of attended reproduction, the cancer coincidence and pregnancy is supposing an increment. However, the more and more precocious beginning of the sexual relationships and the demonstrated relationship among the infections of sexual transmission - overalls the human viral papilloma ${ }^{7,8}$ and the cervical cancer justifies that the growing behavior of the first ones mainly at the end of the second and third decades of life it makes that cases of cancer appear in young ages. 
On the base of the approached knowledge it is evident the growing incidence of the lesions pre-wicked and wicked epithelia's of the uterine neck, to what sinks the displacement of the morbility and mortality toward more and more precocious ages, increases potentially the years of life lost, even appearing in not very usual groups of high risk as the pregnant; formulating the following scientific question: Which will the clinical-epidemic behavior of the cancer of uterine neck be in the Youth's Island in the period 2010-2015?

\section{Methodological design}

It was carried out a retrospective longitudinal descriptive observational study to characterize the behavior of the morbility and mortality for cancer of the uterine neck in patient of the Youth's Island, in the period understood among the years 2003 and 2015, according to clinical variables - epidemic of interest.

The study universe was understood by the 381 patients assisted with this diagnosis in the Consultation of Pathology of Neck of the Hospital General Educational Heroes of the Baire" (HHB) during the period of study, being studied $100 \%$ of them, not being needed of inclusion approaches and exclusion for the conformation of the sample. 17 patients were also included that, still when they died during the period that is analyzed, they had been diagnosed as such before the year 2003

For the gathering of the necessary information for the study the leaves of position of the Consultation of Pathology of Neck were revised, the individual clinical histories of the patients, their cytology cards (in a previously requested copy), the database contained in the software SPIC version 3.0 of the SUMASCOPE and the reports histologic of the Department of Pathological Anatomy of the Hospital Heroes of the Baire". Likewise, the Reports of Cancer and the Registration of Deceased's of this institution were revised for the period of study.

For the prosecution of the data a base data was made in Microsoft Excel 2010, what allowed to determine summary measures for qualitative and quantitative variables as total, average or half arithmetic, percentages? The morbility rates and mortality were calculated by 100 000 women so that they could be comparable to the picked up national values of the Statistical Annuals of this period.

\section{Analysis of the results}

During the period of study 381 patients were diagnosed with cervical cancer, which represented $76 \%$ of all gynecological malignancies for that interval. The year of more occurrence was the 2014 with 93 cases (24\%), followed by the year 2015 with 52 cases (14\%) and the years 2009,2008 and 2010, for that order, with $8 \%$ each one. The years 2004 and 2013 were the years of smaller quantity of diagnose just by 14 cases $(3,7 \%)$ each one. However, the years 2003, 2004 and 2007 were the periods in those that the cervical cancer represented the biggest percentage inside the gynecological cancer with values of 85$88 \%$, while the years 2013 and 2012 were those fewer represented in such a sense with $42 \%$ and $57 \%$, respectively.

The group more affected age was of 41-48 years with the fourth part of the cases $(26 \%)$, followed by the 25-32-year-old group with a fifth part $(21 \%)$ and the 49-56-year-old group with a seventh part of the cases $(14 \%)$. The patients bigger than 64 years represented less than $3 \%$ of the studied sample.

In the year 2013 the biggest age average was presented with 51,9 years, followed by the year 2006 with an age 49,5-year-old average and the year 2004 with 47,3 years. In two years the age average went inferior to the 40 years, the year 2014 with 38,4 years and the 2007 with 39,7 years. The age average for the period 2003-2015 was of 43,6 years.

As for the area of origin health, almost half of the cases $(49,6 \%)$ comes from the Leonilda Tamayo Matos Policlinic 2 ", while the Policlinic 3 Orestes Falls Oñate was that of smaller casuistry with almost the quarter leaves of the cases $(23,9 \%)$. This last area of health however showed a rate of more incidences to the Policlinic 1 Juan Manuel Páez Inchausti when considering the feminine population.

Inside the variables of risk that the literature relates with this cancer he/she was the primipara before the 20 years $(44 \%)$, the beginning of the sexual relationships before the 16 years $(44 \%)$ and the habit of smoking (39\%) in around two of each five patients. Likewise, the use of intra-uterine devices for more than five serial years $(33 \%)$ and the biggest parity at two $(31 \%)$ they were presented in around the third part of the cases, while the use of hormonal contraception for more than five serial years (28\%), the biggest number of abortions at two $(27 \%)$ and the menarquia before the 12 years of age $(27 \%)$ they were present in the fourth part of the cases. The family antecedents of gynecological cancer were only referred the tenth part of the cases.

In spite of not being a grateful variable of risk it is very excellent for this series that eleven pregnant has been diagnosed with this affection, all in the last 24 months. Of the total of these pregnant, more than half of them $(55 \%)$ they were evaluated from the first trimester of the pregnancy, while a fourth part $(27 \%)$ they were evaluated starting from the second trimester and a sixth part (18\%), in the last trimester.

More than the third part of the cases (36\%) they had cytology with cervical dysplasia in the investigation initial and almost similar frequency $(33 \%)$, a positive cytology to cells neoplasm. Of the rest of the patients, the sixth part had a negative cytology; almost the tenth part not had an age understood in the investigation cytology and $7 \%$ a smear with benign alterations.

In almost nine of each ten patients (88\%) a correlation diagnosis existed between the colposcopy and the histology.

In such a sense, it was appreciated that the stadium 0 or in situ it almost represented the fifth three parts $(58 \%)$ of the sample and the stadium I almost the fourth part of the cases (24\%). In smaller frequency the stadium was reported II in the eighth part of the cases $(12 \%)$, the stadium III (5\%) and the stadium IV in $1 \%$. In all the stadiums, the percentages were negative in comparison with the values of the country. The years 2014 and 2012 showed the biggest percentages of precocious diagnosis (stage $0-\mathrm{I}$ ) with 90,3 and $80 \%$, respectively. Contrarily, the years $2003(48 \%)$ and $2013(50 \%)$ they reflected the lowest percentages. Specifically, for the eleven pregnant, in $73 \%$ of them the diagnosis corresponded to the stadium 0 and the rest $(27 \%)$ to the carcinoma micro infiltrator.

This way, the year 2015 were that of more rate with 69,03 for 100 000 women, followed by the year 2014 with 45,23 and the year 2010 with 42,74 . The years of smaller rate were the $2004(14,15), 2012$ $(14,25)$ and $2005(16,5)$.

Of narrow relationship with the previous variables, you could appreciate as the simple hysterectomy or type I it was the used therapeutic modality (40\%), followed by the conization (28\%). $21 \%$ received some modality of treatment adjuvant and only in five cases they were the terminal sick person cares the only therapeutic option. The clinical pursuit in two patients is in relation to two pregnant that 
have not still finished the pregnancy to the moment to edit this report. Related with the clinical stadium in most of the studied was possible to finish with success the period of pregnancy and to define the later treatment to the puerperium.

The year 2012 with seven deceased were the period of more mortality, followed by the years 2004, 2010 and 2014 with six patients in each one. The year 2008 was the period of smaller mortality just by two deaths.

The year 2008 were the only period with an average of the deceased's' age for bigger cervical cancer to 70 years $(77,5)$, while in the years $2009(69,3), 2012(67,3)$ and $2014(66,0)$ the average went bigger to the 65 years. The lowest age averages were in the years 2004 $(54,5)$ and $2013(55,0)$, in that order.

Related with this aspect, we see that the years 2004 (20,2), 2013 $(19,0)$ and $2015(18,3)$ they showed the biggest quantity in years of life potentially lost, I reflect of premature death. In opposed sense, all the deaths of the 2008 overcame the 74 years of age and the years $2009(8,0), 2012(11,3)$ and $2014(11,6)$ they also showed the smallest values.

Finally, the survival in the study sample showed superior values to $85 \%$ to the five years and even, bigger to $95 \%$ in the first 12 months of evolution.

\section{Discussion of the results}

In the year 2005 a tamizaje carried out in low Peru the supervision of the Pan-American Organization of the Health (OPS) it shows a bigger risk of developing the illness in those with ages understood between 35 and 50 years. ${ }^{9}$

Other studies show a bigger prevail to more precocious ages, as the one carried out in Montevideo (Uruguay) in the 2003 where a concentration was observed between the 30 and 49 years with $67 \%$ and below the 29 years it was only located in $24,2 \%{ }^{10}$

In Cuba similar results have been reported. A study carried out in Camagüey in the years 2010-2011 for Gómez Garcia and collaborators checked that the group more affected age was in women among 30-39 years of age, almost half of the cases, fact that belongs together with the revised literature where it is considered this more frequent illness in ages of more sexual activity. ${ }^{11}$ Another national study, of Torriente and Valdés in the Maternity of Guanabacoa points out he/she enters more than 2000 patients studied with cervical neoplasia (lesion precursor) that two thirds of them had less than 40 years of age. ${ }^{12}$

Although a coincident position doesn't exist in the cervical cancer in correspondence with the precocious or late menarquia, like it happens for example to the cancer of it suckles, if it thinks about for some authors that have found certain correspondence among these variables, as Benia and Tellechea in Uruguay in whose study $12,5 \%$ of the cases had a precocious menarquia 10 . Other studies, as that of Castañeda - Toledo showed significance when the menarquia happened before the 10 years or after the 14 years ${ }^{13}$ without place to doubts one of the most important factors in the pathogenic of the cervical cancer is the precocious beginning of the sexual, related activity this with a bigger association probability to infections cervical vaginal and among them, the infection for human papilloma. This way, Benia Tellechea found in Uruguay that one of each five cases of its study began the sex precociously. ${ }^{14}$ In the study of Muñoz and collaborators in Zacatecas, when taking like reference to the women that began its sexual life after the 20 years, is considered that those that made it be- fore the 15 years have a risk twice bigger (RM 2,0 IC95\% 1,2-3,5). ${ }^{15}$ Similar results found Torriente and Valdés ${ }^{12}$ because nine of each ten patients began their sexual relationships before 20 years and six of each ten, before 16 years.

Hernández and collaborators ${ }^{16}$ outline that 18,6 years like average of the beginning of the sexual relationships is decisive for the presence of the neoplasia cervical intraepithelial. Carried out studies ${ }^{17}$ check that the beginning of the sexual relationships in early ages is a factor predisposing due to the changes physiologic metaphasis that take place in the adolescent's cervical epithelium that imply cellular multiplication and if it is present of the agent etiological (VPH) they modify this normal or definitive transformation of the epithelium in atypical metaplasia that can unchain the development of the cervical cancer with the years.

It is considered that the cytology is a not very sensitive technique to detect the presence of the virus of the human papilloma (HPV or VPH), since only it can identify $15 \%$ of the total of cases DNA correctly positive VPH; but diverse studies that have been made in populations that go to the detection programs or to clinical of attention of illnesses of sexual transmission, they notify prevalent that go from $0,24 \%$ to $9-13 \%$, in function of studied population's type 18. In a Mexican study made by Castañeda and Toledo ${ }^{13}$ the percentage of presence of positive signs of HPV for cytology it is of $28,6 \%$. Another study, this in Chihuahua shows that $28 \%$ of its cases was payee of the VPH, while you Wall in Warrior's state - also in Mexico - it only found 9,5\%. ${ }^{18}$

Another element to relate it constitutes the number of childbirths transpelvianos, as well as the age in which happen these childbirths, overalls the primeparisation. The shared data of eight studies of cases and witness on the cancer invasive of the uterine neck and two studies on the carcinoma in situ, made in four continents, they suggest that the women with three or four term pregnancies had a risk higher 2,6 times of appearance of cervical uterine cancer that those that had never given to light; the women with 7 childbirths or more, they presented a risk 3,8 times adult. $^{15}$

The oral contraceptives put on to the disposition of the American women at the beginning of the years sixty. The convenience, effectiveness and reversibility of action of the birth-control pills have made of them the most popular form in control of the birth in United States. However, it has shown certain concern on the paper that have the hormones in some cancer types and the form in that the contraceptives with the help of hormones can contribute in the development of these neoplasity. ${ }^{19}$

The habit of smoking, in the sample studied by Torriente, ${ }^{12}$ was present in $80 \%$ in the moment of the initial interview with more than 10 cigarettes per day. Lecciardone ${ }^{20}$ in their study concluded that it was significant the relationship between the cancer and the tobacco whenever the habit was present, once abandoned the cigarette the risk diminishes quickly.

Well controlled epidemic studies have demonstrated, according to appointment the Pan-American Organization of the Health (OPS) in their report yearly of the year 2006 that the patients with cervical uterine positive cancer to the VPH have double probabilities of having been smoking that the positive witness to the VPH 9. Similar pronouncement had the World Organization of the Health (OMS), when recognizing in its annual characterization of the 2007 that this factor one of the five elements of more excellent risk constitutes in most of the continents. ${ }^{21}$ 
As for the diagnoses colposcopies and histology, these results belong together with those reached in previous studies ${ }^{22}$ carried out in this respect where the colposcopy has always stayed with more than 85 correlation \% with the diagnosis histology; in other national works, Balestena obtained in its study a highly significant correlation and in the Hospital Eusebio Hernández, Goicolea maintained a correlation colpohistological in the period $1996-2006$ of $92,8 \%{ }^{23}$ From the international point of view, Spitzer in the Central Hospital of Asturias obtained a correlation superior colpohistological to $90 \%$.

As it is known, one of the elements that define with more force the therapy to use in each case is the estadiaje from the cancerous illness to the moment of the diagnosis. In the 26th Annual Report on results of the treatment of the Gynecological Cancer of the FIGO for the 2006 is observed that in a series of 15081 studied patients, 1352 were in the stage IA $(9 \%), 5001$ in stage IB $(33,2 \%), 4458$ in stage II $(29,6 \%), 3320$ in stage III (22\%) and 870 patients in stage IV $(5,8 \%)$, meeting these results in agreements with the reported values although it deserves a particular analysis the fact that, in spite of moving toward the stages I and II the biggest number of cases, the incidence in the stage III are almost half of what the FIGO reports what is considered it obeys the global behavior of this last one, where areas are included with very little development of screening programs. ${ }^{24}$

Coincidently to the results of this study, in a series published by González Mariño in the 2007 was found that the distribution for stadiums in this tumor showed the biggest number of cases in state 0 , in 60 women $(48,3 \%)$; followed by the IB, in 28 women $(22,5 \%){ }^{25}$

In the one mentioned report of the FIGO the 2006 they are reported as $21,9 \%$ of the cases they received surgery like only therapeutic modality, $33,2 \%$ was only irradiated, $14,2 \%$ received radio - concurrent chemotherapy and $3,6 \%$ of the patients received initial chemotherapy. 27 remaining\% received treatment outlines combining the previous modalities. ${ }^{25}$

Multiple they are the conditions that define or they influence in the survival of the patient oncological that go from the anatomical localization, the form histological and the stadium in which one makes the diagnosis according to extension tumoral, ganglion and metastasis. Some series of cases show very near values to the opposing ones in this series, when evaluating in a global way the survival of the patients with cancer of the uterine neck. Saslow, Castle and Cox found in the $200792,9 \%$ of survival to the year of diagnosis, $85,4 \%$ to the two years, $81,2 \%$ to the three years, $79,3 \%$ to the four years and $77,3 \%$ to the five years. ${ }^{26}$

Another series like that of Benedet et al. ${ }^{27}$ sample a global survival of the cervical cancer of $65,4 \%$ to the 5 years, ${ }^{27}$ but in the wicked neoplasity of neck diagnosed precociously in stadium IA it would reach $95 \%$ (99,5\% for the stadium Ia1). In stadiums advanced III and IV the survival falls respectively among $38,7 \%$ to $9,4 \%$, being respectively for the stadiums IB and IIA of $81 \%$ and $63,5 \%$.

\section{Conclusion}

Tendency exists to the increment of the morbility for cervical cancer, with decrease of the age appearance average. The primiparidad and beginning of sexual relationships in a precocious way and the nicotinic are related with most of the studied cases, being significant the appearance of this cancer in pregnant and the number of patient without altered cytology. The correlation diagnostics was adapted, prevailing the precocious stadiums and the surgical treatment as initial modality. The mortality for this cancer stayed stable in the period, with slight decrease of the years of life potentially lost in the last five years' period and a high survival to the 5 years of the diagnosis.

\section{Acknowledgements}

None.

\section{Conflicts of interest}

None.

\section{References}

1. Pérez MLJ, Mantilla GY, Pérez BR. Relationship of some epidemic variables in patient with the diagnosis of NIC associated to VPH. Mediciego. 2013;19(2).

2. You toast P, War M, Gallant AND, et al. Incidence and mortality for cancer in the Cuban woman. Triennium 2000-2002. Cuban Rev Med. 2007;46(2).

3. Statistical annual 2006. Ministry of Public Health, Cuba. 2007.

4. Statistical annual 2014. Ministry of Public Health, Cuba. 2015.

5. Hoellen F, Reibke R, Hornemann K, et al. Cancer in pregnancy PART I: basic diagnostic and therapeutic principles and treatment of gynecological malignancies. Arch Gynecol Obstet. 2012;285(1):195205.

6. Azim HA, Azim H, Peccatori FA. Treatment of cancer during pregnancy with monoclonal antibodies: real challenge. Expert Rev Clin Immunol. 2010;6(6):821-826.

7. Gambino TO, Gorio TO, Carrara L, et al. Cancer in pregnancy: maternal and fetal implications on decision-making. Eur J Gynecol Oncol. 2011;32(1):40-45.

8. Yamazaki T, Inaba $\mathrm{F}$, Takeda $\mathrm{N}$, et al. To study of abnormal cervical cytology in pregnant women. Arch Gynecol Obstet. 2006;273(6):274 277.

9. Pan-American organization of the Health. Prevention of the cérvicouterine cancer in the Peru. Learned lessons of the demonstrative project TATI. 2006

10. Benia W, Tellechea G. Study of the factors of risk for cancer of he/she suckles and uterine neck in women users of three policlínicas mires of Montevideo. Rev Med Uruguay. 2004;16:103-113.

11. Gómez García L, González Sáez AND, Cáceres Pineda MA, et al (2012) Characterization with altered organic cytology. Cuban Rev Obstet Ginecol. 2004;38(3):378-388.

12. Torriente Hernández S, Valdés Álvarez OR, et al. Characterization of a group of patients with cervical intraepithelial neoplasia diagnosed by diathermic loop biopsy. Cuban Rev Obstet Ginecol. 2011;37(1):42-53.

13. Castañeda Iñiguez MS, Toledo Cisneros R, Aerie Delgadillo M. Factors of risk for cancer uterine cérvico in women of Zacatecas. Public health Mex. 2008;40(4):330-338

14. Smith JS, Green J, Gonzalez AB, et al. Cervical cancer and uses of hormonal contraceptives: To systematic review. Lancet. 2013;361(9364):1159-1167.

15. Muñoz N, Bosch FX, Sanjosé S, et al. The virus of the human papiloma in the etiología of the cancer uterine cervical. PAHO BULL. 2013;115:301-309.

16. Hernández Hernández DMK, German Hernández FR, Adorn it Bernal THE, et al. Cancer of uterine neck. Social, clinical and reproductive factors associated with lesions precursors. Rev Med IMSS. $2009 ; 39(4): 325-333$ 
17. Rodríguez Saves TO, Echevarría Aerie TO, Murla Alonso P, et al Factors of risk of the cancer cérvix in the Municipality Hill. Cuban Rev Hig Epidemiol. 2010;37(1):40-46.

18. Sandoval walls RJ, García MGA, Durán GIVES, et al. Cancer uterine cérvico: Factors of risk and alterations associated in women of Warrior's state. Rev Inst Nal Cancerol (Mex). 2008;44(1):19-27.

19. Blackish Herrera ME, Pérez Rivero JL, Camacho Vázquez M, et al. Behavior of the organic cytologies altered in an area of health. Cuban Rev Obstet Ginecol. 2012;38(4):510-520.

20. Lecciardone JC, Brownson RC, Chang JC, et al. Risk of cancer of uterine cérvix in cigarillos smokers. Am J Prev Med. 2010;26(2):274-281.

21. Bosch FX, Manos MM, Muñoz N, et al. Prevalence of Human Papillomavirus in Cervical Cancer: To Worldwide Perspective. J Nat Cancer Inst. 1995;87(11):796-802.

22. Torriente Hernández S, Valdés Álvarez OR, Villarreal Martínez TO, et al. Correlation colpohistological in the patient portadoras of neoplasia cervical intraepitelial tread with radiosurgery. Cuban Rev Obstet Ginecol. 2011;37(1):23-41.
23. Balestena JM, Suárez BC, Pilot MM, et al. Correlation among the diagnosis cytological, colposcopic and biopsy directed with the diagnosis histological by conization. Cuban Rev Obstet Ginecol. 2004;30(3):16-30.

24. 26th Annual Report on the results of treatment in Gynecological Cancer. Int J Ginecol Obstet. 2006;95(1):43-192.

25. González Mariño MA. Gynecological Cancer in the Clinic San Pedro Claver. Rev Colomb Cancerol. 2007;11(2):87-91.

26. Saslow D, Castle PE, Cox JT, et al. American Cancer Society Guideline for Human Papillomavirus (HPV) Vaccine uses to prevent cervical cancer and its precursors. CA Cancer J Clin. 2007;57(1):7-28.

27. Quinn MA, Benedet J, Odicino F, et al. Carcinoma of the cervix uteri. FIGO 26th Annual Report on the results of treatment in gynecological cancer. Int J Gynaecol Obstet. 2006;95(Suppl 1):S43-S103. 